\title{
Setting the Record Straight: Correcting Two Recent Cases of Materialist Misrepresentation of My Research and Conclusions
}

\author{
Pim van Lommel, M.D. \\ Velp, The Netherlands
}

\begin{abstract}
In two recent publications, one by Dean Mobbs and Caroline Watt and the other by Kevin Nelson, I was surprised to find my and my colleagues' 2001 article in the Lancet misrepresented. In this Editorial, I attempt to correct those misrepresentations and to discuss them with regard to responsible scholarship in the ongoing debate in the professional literature about the relationship of mind and brain.
\end{abstract}

KEYWORDS: near-death experience, consciousness, mind-brain relationship

In light of the current controversy about the relationship between mind and brain, to which near-death experience (NDE) research contributes uniquely, I was rather surprised on two recent occasions to find publications in which my research and conclusions had been totally misrepresented. Both publications were written by authors who appear to subscribe to a materialist philosophy_holding that all mental phenomena can be explained by neurochemical mechanisms in the brain. Because my own research on NDEs has led me to a different position, I am dismayed to see my work used in arguments against the very philosophy to which I subscribe. In this Editorial, I detail the two cases, providing corrective information, and comment on the role

\footnotetext{
Pim van Lommel, M.D., is a retired cardiologist and an author and speaker. He acknowledges that the content of this Editorial is based partly on the text in some paragraphs in Chapter 8 of van Lommel (2010). Correspondence regarding this Editorial should be directed to Dr. van Lommel at e-mail: pimvanlommel@gmail.com.
} 
these cases play in the ongoing professional dialog about the relationship between mind and brain.

\section{Dean Mobbs and Caroline Watt's 2011 Article}

One case involved a late 2011 article in Trends in Cognitive Sciences by Dean Mobbs at the University of Cambridge and Caroline Watt at the University of Edinburgh. They entitled their article, "There is nothing paranormal about near-death experiences: how neuroscience can explain seeing bright lights, meeting the dead, or being convinced you are one of them." In it, the authors presented evidence leading to their conclusion that "Taken together, the scientific evidence suggests that all aspects of the near-death experience have a neurophysiological or psychological basis" (p. 449). Although I actually find many points to critique in this article, I understand that Janice Holden and Bruce Greyson are preparing a manuscript to comprehensively review the article, so I'll restrict myself to those points related to my and my colleagues' work.

In their article, Mobbs and Watt (2011) twice referenced my and my colleagues' 2001 publication in the Lancet in which we described our longitudinal prospective study of NDEs in 10 Dutch hospitals. In Mobbs and Watt's article, our publication was Reference [2]. In one of the two cases, Mobbs and Watt referenced our publication accurately: "In one study [2], of those who had had a near-death experience, 50\% reported an awareness of being dead, 24\% said that they had had an out-of-body experience, $31 \%$ remembered moving through a tunnel, and $32 \%$ reported meeting with deceased people" (p. 447). However, the second paragraph of Mobbs and Watt's article reads:

Yet a handful of scientific studies of near-death experiences do exist. One example is a case study in which a patient with diabetes reported a near-death experience during an episode of hypoglycaemia (too low blood sugar). During this episode, the patient was in a sleep-like state with rapid eye movement (REM) - a common marker of dreaming and thought to underlie the consolidation of memories, a process that may explain life reviews during near-death experiences (e.g. where the individual re-experiences or relives events from their life). Despite not being in danger of dying, upon resuscitation, the patient recounted many of the classic features of the near-death experience [2]. (p. 447)

Our Lancet article includes no reference to any such case of hypoglycaemia/REM/NDE. Indeed, I am not aware of such a case in our research. Beyond this wrong citation of our work, I find fault with 
the presentation of one case that implicates processes that my own research — cited in that very Lancet article-has shown to be inadequate as neurophysiological explanation. For example, among the many patients who have experienced life reviews during NDEs associated with cardiac arrest, REM could not account for their life reviews, as their brains appeared not to be functioning at all-a phenomenon I will explain in depth later in this Editorial. In addition, although my own research involved patients who were resuscitated from cardiac arrest, a well-established literature exists indicating that NDEs of people not near-death and those of people clinically dead are indistinguishable; thus, proximity to death seems not to be an important variable in understanding NDE contents and aftereffects.

Ironically, the one case we did present in our Lancet article was of Mr. B. This patient arrived at hospital in cardiac arrest, with ventricular fibrillation on his EKG, comatose, with no body and brainstem reflexes, with widened pupils not reacting to light, and without respiration. He was successfully resuscitated but still comatose for about one week. Upon regaining consciousness, he recognized the male nurse that had been involved in his resuscitation, and he accurately reported where the nurse had placed the patient's dentures that he had removed from the patient's mouth during the resuscitation. The patient reportedly had observed this action and the entire resuscitation procedure from a position of perceptual clarity above the resuscitation scene. Thus, in explicit contradiction to Mobbs and Watts's (2011) article title, the one case we did present did explicitly contain so-called "paranormal" features-the ability to perceive accurately during a time that repeated measurement of reflexes during resuscitation indicated total absence of brain function. Mobbs and Watts did not mention this case, presumably because it cannot be explained by current neurophysiological theories and, thus, does not support their thesis.

Finally, our concluding sentence in the Lancet article, for which we had laid the groundwork with previous results and discussion in the article, was "Finally, the theory and background of transcendence should be included as a part of an explanatory framework for these experiences" (p. 2044). Mobbs and Watt did not mention any of our results, discussion, or conclusion-all of which had already shown the inadequacy of neurophysiological or psychological mechanisms to explain NDE occurrence and contents and, thus, directly contradicting their own stated conclusion.

I am deeply concerned that articles like Mobbs and Watt's are pass- 
ing the peer review process when the authors did not even acknowledge, more or less actually address, existing literature that contradicts their stated position. I can only hope that seriously interested scholars and professionals, who seek a complete perspective on NDEs in general and on the current professional dialog about the mind-brain relationship in particular, take the time to follow up on what authors of referenced material actually said-and I believe they should conduct literature searches themselves that lead them to the full range of perspectives, including recent works such as mine (van Lommel, 2010); Holden, Greyson, and James' (2009); and Kelly, Greyson, and Kelly's (2007).

\section{Kevin Nelson's The Spiritual Doorway in the Brain}

While reading Kevin Nelson's (2011) book, The Spiritual Doorway in the Brain, I was once again surprised when I reached page 132. There he wrote that that he, as a neurologist, was stunned after reading my and my colleagues' Lancet article. He wrongly presumed that in this article my co-authors and I stated that clinical death was equal to brain death.

As lead author of that article, and as author of the book Consciousness Beyond Life (van Lommel, 2010) in which I addressed the same subject, I can state unequivocally that Nelson's presumption was incorrect. Rather, in both publications, we and I stated explicitly that in patients with an acute myocardial infarction who experience cardiac arrest, the entire brain is deprived of oxygen, resulting in the loss of consciousness, body- and brainstem reflexes, and respiration. This condition is known as clinical death. It is usually reversible, that is, temporary, if resuscitation is started within five to ten minutes. But a long delay in resuscitation may result in the death of a great many brain cells and thus in brain death; most of these patients will ultimately die. To quote the Lancet article:

We defined clinical death as a period of unconsciousness caused by insufficient blood supply to the brain because of inadequate blood circulation, breathing, or both. If, in this situation, CPR is not started within $5-10 \mathrm{~min}$, irreparable damage is done to the brain and the patient will die. (p. 2040) 
In the Lancet study my colleagues and I had a record of the electrocardiogram, or EKG, for all patients with cardiac arrest who were included in our study. An EKG displays the electrical activity of the heart. In cardiac arrest patients this EKG record always displays a normally lethal arrhythmia (ventricular fibrillation) or an asystole (a flat line on the EKG).

Obviously, and contrary to what Nelson presumed, cardiac arrest and fainting have totally different effects on the brain and the heart. Cardiac arrest causes anoxia (total lack of oxygen) of the brain, and this life-threatening situation can be restored only by defibrillation (an electric shock), whereas fainting causes hypoxia (less oxygen than normal) to the brain caused by a lower blood pressure but with a normal heartbeat, and so fainting is always spontaneously reversible without the need of resuscitation.

The most important question is of course: Has contemporary research revealed exactly what happens in the brain during cardiac arrest, when the heart stops beating? Through many studies with induced cardiac arrest in both human and animal models, it is now known the complete cessation of cerebral blood flow immediately following ventricular fibrillation (Gopalan, Lee, Ikeda, \& Burch, 1999) results in loss of function of the cortex accompanied by sudden loss of consciousness and of all body reflexes and also results in the abolition of brainstem activity accompanied by loss of all brainstem-reflexes including loss of the gag reflex and the corneal reflex and occurrence of fixed and dilated pupils (van Lommel, 2010). In addition, the function of the respiratory center, located close to the brainstem, fails, resulting in apnea (no breathing).

The brain accounts for only $2 \%$ of overall body weight, but it uses $15-20 \%$ of the body's total energy supply, primarily for maintaining the membrane potential (the electric charge across a cell membrane) of the nerve cells, or neurons. Total loss of oxygen supply (anoxia) causes a functional loss of all cell systems and organs in the body. However, in anoxia of only some minute's duration (transient anoxia) this loss may be temporary, whereas in prolonged anoxia cell death occurs with permanent functional loss. Some cells respond better to anoxia than others. Neurons respond badly, because their sole source of energy is glucose. Unlike the muscle cells in the body, the brain does not store glucose in the form of glycogen as a ready supply of cell energy. The parts of the brain that are most susceptible to anoxia are the neurons in the cerebral cortex as well as those in the hippocampus and the thalamus; which form an important link between the brainstem 
and cerebral cortex (Fujioka et al., 2000; Kinney, Korein, Panigraphy, Dikkes, \& Goode, 1994). The total loss of oxygen supply reduces these structures to utter chaos and wipes out their connections. Synapses are the junctions that enable communication between neurons, and when these synapses stop functioning, cooperation and coordination between neuronal networks in the brain is no longer possible.

If the absence of blood flow to the brain ("no-flow") prevents the supply of glucose and oxygen, a neuron's first symptom will be the inability to maintain its membrane potential, resulting in the loss of neuronal function (van Dijk, 2004). The acute loss of electrical and synaptic activity in neurons can be seen as the cell's inbuilt defense and energysaving response and is called a "pilot light state." When the electrical functions of neurons cease, the remaining energy sources can be deployed very briefly for the cell's survival. In the case of short-term oxygen deficiency, such as remediated cardiac arrest, dysfunction can be temporary and recovery is still possible because the neurons will remain viable for a few minutes after onset of arrest. However, within seconds of onset, a cardiac arrest will result in a total loss of oxygen supply and a build-up of carbon dioxide $\left(\mathrm{CO}_{2}\right)$ in the brain. This situation, which is defined as "clinical death," cannot be remedied during the resuscitation procedure itself but can be remedied only after the cardiac rhythm has been reestablished through defibrillation. A delay in starting adequate resuscitation may result in the death of a great many brain cells and thus in brain death; most patients in such cases will ultimately die. A study carried out at a coronary care unit has shown that patients whose resuscitation was started within one minute had a $33 \%$ chance of survival, compared to only $14 \%$ for those who, due to circumstances, were resuscitated only after more than a minute following the onset of unconsciousness (Herlitz, Bang, Alsen, $\&$ Aune, 2000).

Research has shown that external heart massage during CPR cannot pump enough blood to the brain to restore brain function. Nobody has ever regained consciousness during external resuscitation of the heart. Return to consciousness always requires defibrillation to reestablish cardiac rhythm. Without restoration of normal blood pressure and the resumption of cardiac output, which can be achieved only by successful defibrillation, a long duration of CPR is considered an indication of poor outcome and high mortality because CPR alone cannot ultimately prevent the irreversible damage of brain cells (Peberdy et al., 2003). During CPR, blood supply to the brain is $5-10 \%$ of its normal volume (White et al., 1983), and during external heart mas- 
sage the systolic pressure will usually reach approximately $50 \mathrm{mmHg}$, with an average of $20 \mathrm{mmHg}$ because of the low diastolic pressure. The maximum average blood pressure during proper resuscitation is 30-40 mmHg (Paradis, Martin, \& Goetting, 1989), which is still far too low for the blood to deliver enough oxygen and glucose to the brain. The administration of certain medication during resuscitation can increase blood pressure a little (Paradis, Martin, \& Rosenberg, 1991), but it will remain well below normal. Furthermore, in the absence of a normal blood supply, the brain cells are likely to swell (edema), which results in increased pressure in the brain (intracranial pressure), and also an increase of cerebral vascular resistance occurs. Animal studies have revealed that a higher than normal blood pressure is required to maintain adequate cerebral perfusion and to supply the brain with sufficiently oxygenated blood and to enable the removal of $\mathrm{CO}_{2}$ (Fisher \& Hossman, 1996). During resuscitation, blood gases (oxygen and $\mathrm{CO}_{2}$ ) are sometimes measured to determine the severity of the oxygen deficiency in the blood. However, normal levels of oxygen and $\mathrm{CO}_{2}$ do not guarantee that enough arterial blood, and thus enough oxygen, will reach the brain during resuscitation.

To summarize: Research has established that proper resuscitation, with adequate external heart massage and mouth-to-mouth respiration or respiration via a mask, will produce minimal blood flow ("low-flow") to the brain, which increases the chances of recovery of brain function after the cardiac arrest has been successfully treated with defibrillation. By this minimal cerebral blood flow the no-longerfunctioning neurons will be able to survive for a longer period of time in the minimal energy, pilot light state-also called "hibernation" or "ischemic penumbra" of the brain (Coimbra, 1999), because it prolongs the period of reversibility (viability) before neuronal cell death and brain death occur.

But how can it be determined definitively that the EEG is flat in patients with cardiac arrest, and how can researchers study this question? In normal circumstances no attempts are made to register an EEG during cardiac arrest, because the EEG assessment process takes far too much time, and patients need to be successfully resuscitated and defibrillated as soon as possible. But in some circumstances the electrical activity of the brain has been measured (EEG) during a cardiac arrest, for example during surgery. Following the cardiac arrest (no-flow), the EEG flat-lined after an average of 15 seconds and remained flat despite external resuscitation (low flow) (Clute \& Levy, 1990; Hossmann \& Kleihues, 1973; Losasso, Muzzi, Meyer, \& Shar- 
brough, 1992; Moss \& Rockoff, 1980). A persistent flat-line EEG during external CPR has also been shown in animal studies (Bircher, Safar, \& Stewart, 1980). Monitoring of the electrical activity of the cortex (EEG) has shown that the first ischemic changes during induced cardiac arrest in humans are detected an average of 6.5 seconds after circulatory arrest. Ischemic changes in the EEG show a decrease of power in fast activity and in delta activity and an increase of slow delta I activity, sometimes also an increase in amplitude of theta activity, progressively and ultimately declining to iso-electricity. But more often initial slowing and attenuation of the EEG waves is the first sign of cerebral ischemia. With prolongation of the cerebral ischemia, progression to a flat-line EEG always occurs within 10-20 (mean 15) seconds from the onset of cardiac arrest (Clute \& Levy, 1990; De Vries, Bakker, Visser, Diephuis, \& van Huffelen, 1998; Losasso et al., 1992; Parnia \& Fenwick, 2002), and the EEG remains flat during the cardiac arrest until cardiac output has been restored by defibrillation (Fisher \& Hossman, 1996; Marshall, Lazar, Spellman, Young, Duong, Joshi, \& Ostapkovich, 2001). In tests on animals, auditory evoked potentials, or measures of brain-stem viability, can no longer be induced, which means that the reaction caused in a normal functioning brainstem by sound stimulation is no longer produced (Brantson, Ladds, Symon, \& Wang, 1984; Gua, White, \& Batjer, 1995).

If the cardiac arrest lasts longer than 37 seconds, the EEG will not normalize immediately after cardiac output has resumed. Despite maintaining normal blood pressure in the period following resuscitation, this normalization ultimately depends on the duration of the cardiac arrest. After a complicated resuscitation with persistent coma it can take hours to days for the EEG to get back to normal (Mayer \& Marx, 1972; Smith, Levy, Maris, \& Chance, 1990). The longer the cardiac arrest, the greater the brain damage, the longer the coma, and the longer the EEG remains flat or highly irregular. Furthermore, normalization of the EEG may actually create an overly positive impression of the recovery of the brain's metabolism. Following restoration of the heartbeat and blood circulation, oxygen uptake in the brain may be reduced for a considerable period of time, which is caused by the so-called "reperfusion injury" (Buunk, van der Hoeven, \& Meinders, 2000; Losasso et al., 1992; Mayer \& Marx, 1972). Also in animal studies with induced cardiac arrest the post-arrest cortical hypoperfusion syndrome is prolonged with cortical flow remaining below $20 \%$ of normal up to 18 hours post arrest (White et al., 1983). 
Patients with a myocardial infarction who suffer a cardiac arrest in the coronary care unit will usually be successfully resuscitated within 60-120 seconds; at a nursing ward, however, this will take at least two to five minutes. In the event of a cardiac arrest in the street (a socalled "out-of-hospital" arrest), it will take, at best, five to ten minutes for a patient to be successfully resuscitated, but usually longer, resulting in the death of nearly 90\% (82-98\%) of these patients (De VreedeSwagemakers. Gorgels, Dubois-Arbouw, van Ree, Daemen, Houben, \& Wellens, 1997; Lombardi, Gallagher, \& Gennis. 1994). So it seems rational to assume that all 562 survivors of cardiac arrest in several recently published prospective studies on NDE should have had a flat EEG, because no patient had been resuscitated within 20 seconds of cardiac arrest onset (van Lommel, 2010).

So there are good reasons to assume that consciousness does not always coincide with the functioning of the brain: Enhanced consciousness, with unaltered self-identity, can sometimes be experienced separately from the body. The quite often-proposed objection that a flat line EEG does not rule out any brain activity, because it is mainly a registration of electrical activity of the cerebral cortex, misses the mark. The issue is not whether there is any non-measurable brain activity of any kind whatsoever but whether there is measurable brain activity of the specific form, and in different neural networks, as regarded by contemporary neuroscience to be the necessary condition of conscious experience. And it has been proven in several studies in patients with induced cardiac arrest that there was no such measurable and specific brain activity during cardiac arrest. Additionally, research drawing on magnetic resonance imaging (fMRI) has shown that the joint and simultaneous activity of the cerebral cortex and brainstem with their shared pathways (hippocampus and thalamus) is a prerequisite for conscious experience. As stated previously, exactly these parts of the brain-the neurons in the cerebral cortex, the hippocampus, and the thalamus-are most susceptible to oxygen deficiency (Fujioka et al., 2000; Kinney et al., 1994). A flat line EEG is also one of the major diagnostic tools for the diagnosis of brain death, and in those cases the objection about not ruling out any brain activity whatsoever is never mentioned. Moreover, although measurable EEG activity in the brain can be recorded during deep sleep (non-REM phase) or during general anaesthesia, no consciousness is experienced because there is no integration of information and no communication between the different neural networks (Alkire \& Miller, 2005; Alkire, Hudetz, \& Tononi, 
2008; Massimini, Ferrarelli, Huber, Esser, Singh, Y Tononi, 2005). So even in circumstances where brain activity can be measured, sometimes no consciousness is experienced.

A functioning system for communication between neural networks with integration of information seems essential for experiencing consciousness, and this system does not occur during deep sleep or anaesthesia (Ferrarelli et al., 2010), let alone during cardiac arrest, based on the fact that, as previously stated, a complete loss of brain function during induced cardiac arrest has been demonstrated in several human and animal studies. Thus, during cardiac arrest a non-functioning brain with a flat line EEG does not implicate that the brain is dead nor that all neuronal networks must have died: During clinical death, which is the period of complete cessation of cerebral perfusion during cardiac arrest, there is a transient loss of all functions of the cortex and brainstem until adequate circulation and blood pressure are successfully restored by defibrillation.

\section{Conclusion}

Recently four prospective NDE studies (Greyson, 2003; Parnia, Waller, Yeates, \& Fenwick, 2001; Sartori, 2006; van Lommel et al., 2001) all reached one and the same conclusion: Consciousness, with memories and occasional perception, can be experienced during a period of unconsciousness - that is, during a period when the brain shows no measurable activity and all brain functions, such as body reflexes, brainstem reflexes, and respiration, have ceased. It appears that at such a moment a lucid and enhanced consciousness can be experienced independently of the brain and body. This conclusion was reached on the basis of compelling evidence that the NDE occurs during the period of clinical death and not shortly before or after the cardiac arrest. It was the studies' prospective design that enabled researchers to arrive at this conclusion. If the cardiac arrest involved an NDE with clear perception of the patient's surroundings, its contents could be verified immediately after the report. The precise onset of an NDE is important because it rules out any conclusion other than that the NDE is experienced at a point in time when the brain shows no activity and all brain function has ceased. If the prevailing hypothesis-that consciousness is produced by the brain-were correct, there could be no sign of consciousness nor perception from a position out and above the lifeless body at the moment when the brain shows no activity.

I consider it a highly regrettable situation that people seeking com- 
prehensive, up-to-date information regarding the consciousness-brain relationship question might turn to Mobbs and Watt's article-trusted for its authorship by professionals with university positions-and Nelson's book-trusted for its authorship by a prominent neurologistand unknowingly find incomplete and misrepresented information that supports an erroneous conclusion. The professional dialog regarding the mind-brain relationship has the potential to revise the current prevailing materialist premise that brain produces mind and, thereby, to affect a fundamental paradigm shift regarding the prevailing perspective on the nature of consciousness. Publications that present only selected aspects of the debate and misrepresent some aspects do a disservice to science and to humanity. The dialog will advance only if scholars-and peer reviewers-exercise conscientiousness in making sure that publications both acknowledge and address all available data pertaining to the debate. It is my hope that this editorial advances the dialog by calling attention to these issues of comprehensive and accurate representation of existing literature and by referring readers to sources that provide current findings and conclusions of recently published scientific studies on consciousness during cardiac arrest and other sources that circumspectly address the debate about the nature of mind and brain.

\section{References}

Alkire, M. T., \& Miller, J. (2005). General anesthesia and the neural correlates of consciousness. Progress in Brain Research, 150, 229-244.

Alkire, M. T., Hudetz, A. G., \& Tononi, G. (2008). Consciousness and anesthesia. Science, 322(5903), 876-880.

Bircher N., Safar P., \& Stewart R. (1980). A comparison of standard, 'MAST'augmented, and open chest CPR in dogs: A preliminary investigation. Critical Care Medicine, 8(3), 147-152.

Brantson, N. M., Ladds, A., Symon, L., \& Wang, A. D. (1984). Comparison of the effects of ischaemia on early components of the somatosenseory evoked potential in brainstem, thalamus, and cerebral cortex. Journal of Cerebral Blood Flow Metabolism, 4, 68-81.

Buunk, G., van der Hoeven, J. G., \& Meinders, A. E. (2000). Cerebral blood flow after cardiac arrest. Netherlands Journal of Medicine, 57, 106-112.

Clute, H., \& Levy, W. J. (1990). Electroencephalographic changes during brief cardiac arrest in humans. Anesthesiology, 73, 821-825.

Coimbra, C. G. (1999). Implications of ischemic penumbra for the diagnosis of brain death. Brazilian Journal of Medical and Biological Research, 32, 14791487.

De Vreede-Swagemakers, J. J. M., Gorgels, A. P. M., Dubois-Arbouw, W. I., van Ree, J. W., Daemen, M. J. A. P., Houben, L. G. E., \& Wellens, H. J. J. (1997). 
Out-of-hospital cardiac arrest in the 1990's: A population-based study in the Maastricht area on incidence, characteristics and survival. Journal of the American College of Cardiology, 30, 1500-1505.

De Vries, J. W., Bakker, P. F. A., Visser, G. H., Diephuis, J. C., \& van Huffelen, A. C. (1998). Changes in cerebral oxygen uptake and cerebral electrical activity during defibrillation threshold testing. Anesthesia and Analgesia, 87, 16-20.

Ferrarelli, F., Massimini, M., Sarasso, S., Casali, A., Riedner, B. A., Angelini, G., ... Pearce R. A. (2010). Breakdown in cortical effective connectivity during midazolam-induced loss of consciousness Proceedings of the National Academy of Sciences of the United States of America, 107, 2681-2686.

Fisher, M., \& Hossman, K. A. (1996). Volume expansion during cardiopulmonary resuscitation reduces cerebral no-reflow. Resuscitation, 32, 227-240.

Fujioka, M., Nishio, K., Miyamoto, S., Hiramatsu, K.I., Sakaki, T., Okuchi, K., . . Fujioka, S. (2000). Hippocampal damage in the human brain after cardiac arrest. Cerebrovascular Disease, 10, 2-7.

Gopalan, K. T., Lee, J., Ikeda, S., \& Burch, C. M. (1999). Cerebral blood flow velocity during repeatedly induced ventricular fibrillation. Journal of Clinical Anesthesia, 11, 290-295.

Greyson, B. (2003). Incidence and correlates of near-death experiences in a cardiac care unit. General Hospital Psychiatry, 25, 269-276.

Gua, J., White, J. A., \& Batjer, H. H. (1995). Limited protective effects of etomidate during brainstem ischemia in dogs. Journal of Neurosurgery, 82, 278-284.

Herlitz, J., Bang, A., Alsen, B., \& Aune, S. (2000). Characteristics and outcome among patients suffering from in-hospital cardiac arrest in relation to the interval between collapse and start of CPR. Resuscitation, 53, 21-27.

Holden, J. M., Greyson, B., \& James, D. (Eds.). (2009). The handbook of neardeath experiences: Thirty years of investigation. Santa Barbara, CA: Praeger/ ABC-CLIO.

Hossmann, K. A., \& Kleihues, P. (1973). Reversibility of ischemic brain damage. Archives of Neurology, 29, 375-384;

Kelly, E. W., Greyson, B., \& Kelly, E. F. (2007). Unusual experiences near death and related phenomena. In E. F. Kelly, E. W. Kelly, A. Crabtree, A. Gauld, M. Grosso, \& B. Greyson, Irreducible mind: Toward a psychology for the 21st century (pp. 367-421). Lanham, MD: Rowman and Littlefield.

Kinney, H. C., Korein, J., Panigraphy, A., Dikkes, P., \& Goode, R. (1994). Neuropathological findings in the brain of Karen Ann Quinlan. The role of the thalamus in the persistent vegetative state. New England Journal of Medicine, 330, 1469-1475.

Lombardi, G., Gallagher, E. J., \& Gennis, P. (1994). Outcome of out-of-hospital cardiac arrest in New York City: The pre-hospital arrest survival evaluation (PHASE) study. Journal of the American Medical Association, 271, 678-683.

Losasso, T. J., Muzzi, D. A., Meyer, F. B., \& Sharbrough, F. W. (1992). Electroencephalographic monitoring of cerebral function during asystole and successful cardiopulmonary resuscitation. Anesthesia and Analgesia, 75, 12-19.

Marshall, R. S., Lazar, R. M., Spellman, J. P., Young, W. L., Duong, D. H., Joshi, S., \& Ostapkovich, N. (2001). Recovery of brain function during induced cerebral hypoperfusion. Brain, 124, 1208-1217.

Massimini, M., Ferrarelli, F., Huber, R., Esser, S. K., Singh, H., \& Tononi, G. 
(2005). Breakdown of cortical effective connectivity during sleep. Science, 309, 2228-2232.

Mayer, J., \& Marx, T. (1972). The pathogenesis of EEG changes during cerebral anoxia. In J. H. A. van der Drift (Ed.), Cardiac and vascular diseases / Handbook of electroencephalography and clinical neurophysiology (Vol. 14A, Part A, pp. 5-11). Amsterdam, The Netherlands: Elsevier.

Mobbs, D., \& Watt. C. (2011). There is nothing paranormal about near-death experiences: how neuroscience can explain seeing bright lights, meeting the dead, or being convinced you are one of them. Trends in Cognitive Sciences (15), 447-449.

Moss, J., \& Rockoff , M. (1980). EEG monitoring during cardiac arrest and resuscitation. Journal of the American Medical Association, 244, 2750-2751.

Nelson, K. (2011). The spiritual doorway in the brain: A neurologist's search for the god experience. New York, NY: Dutton.

Paradis, N. A., Martin, G. B., \& Goetting, M. G. (1989). Simultaneous aortic jugular bulb, and right atrial pressures during cardiopulmonary resuscitation in humans: Insights into mechanisms. Circulation, 80, 361-368.

Paradis, N. A., Martin, G. B., \& Rosenberg, J. (1991). The effect of standard and high dose epinephrine on coronary perfusion pressure during prolonged cardiopulmonary resuscitation. Journal of the American Medical Association, 265, 1139-1144.

Parnia, S., \& Fenwick, P. (2002). Near-death experiences in cardiac arrest: Visions of a dying brain or visions of a new science of consciousness. Review article. Resuscitation, 52, 5-11.

Parnia, S., Waller, D. G., Yeates, R., \& Fenwick, P. (2001). A qualitative and quantitative study of the incidence, features and aetiology of near death experience in cardiac arrest survivors. Resuscitation, 48, 149-156.

Peberdy, M. A., Kaye, W., Ornato, J. P., Larkin, G. L., Nadkarni, V., Mancini, M. E, . . Lane-Truitt, T. (2003). Cardiopulmonary resuscitation of adults in the hospital: A report of 14720 cardiac arrests from the National Registry of Cardiopulmonary Resuscitation. Resuscitation, 58, 297-308.

Sartori, P. (2006). The incidence and phenomenology of near-death experiences. Network Review: Journal of the Scientific and Medical Network, 90, 23-25.

Smith, D. S., Levy, W., Maris, M., \& Chance, B. (1990). Reperfusion hyperoxia in the brain after circulatory arrest in humans. Anesthesiology, 73, 12-19.

van Dijk, G. W. (2004). Bewustzijn [Consciousness]. In B. T. J. Meursing \& R. G. van Kesteren (Eds.), Handboek reanimatie [Handbook resuscitation] (2nd rev. ed., pp. 21-25). Utrecht, The Netherlands: Wetenschappelijke Uitgeverij Bunge.

van Lommel, P. (2010). Consciousness beyond life. The science of the near-death experience. New York, NY: Harper Collins.

van Lommel, P., van Wees, R., Meyers, V., \& Elfferich, I. (2001). Near-death experiences in survivors of cardiac arrest: A prospective study in The Netherlands. Lancet, 358, 2039-2045.

White, B. C., Winegan, C. D., Jackson, R. E., Joyce, K. M., Vigor, D. N., Hoehner, T. J., . . Wilson, R. F. (1983). Cerebral cortical perfusion during and following resuscitation from cardiac arrest in dogs. American Journal of Emergency Medicine, 1, 128-138. 